\title{
Proteccionismo inverso y política comercial dentro del sistema multilateral de comercio: el caso de las restricciones a la exportación
}

Reverse protectionism and trade policy on multilateral
trading system: the case of export restraints

Protecionismo reverso e política comercial dentro do sistema multilateral de comércio: o caso das restrições à exportação

Jose Jaime Baena Rojas ${ }^{1}$

DOI: 10.5752/P.2317-773X.2019v7.n3.p28

Recibido el 24 de septiembre de 2018

Aprobado el 10 de noviembre de 2018

\begin{abstract}
RESUMEN
Desde la creación de la OMC se han recibido algunas demandas por parte de sus estados membros, todo ello respecto a la adopción de restricciones a las exportaciones. Dicha práctica suponen la configuración de un nuevo tipo de proteccionismo denominado "proteccionismo inverso" el cual no parece estar regulado a cabalidad por las disposiciones del GATT. Si bien algunos de sus artículos parecen arrojar cierta luz sobre el tema, por lo que se han invocado en algunas de las diferencias de las existentes hasta la fecha-como el "Articulo VIII Derechos y Formalidades referentes a la importación y a la exportación” y el "Artículo XI Eliminación General de las Restricciones Cuantitativas", entre otros- resulta evidente la incapacidad del GATT y la OMC para remediar esta situación. Por lo tanto, dada esta carencia, es crucial dentro del sistema multilateral de comercio que se conduzca un nuevo proceso de negociación en el que se desarrolle un acuerdo definitivo que regule este tipo de políticas comerciales.
\end{abstract}

Palabras clave: Proteccionismo inverso. Restricciones a la exportación. Sistema multilateral de comercio. GATT. OMC.

\section{ABSTRACT}

Since the creation of the WTO, some lawsuits have been received from its member states regarding the adoption of export restrictions. This trade policy assumes a new kind of protectionism dubbed "reverse protectionism" which does not seem to be fully regulated by GATT provisions. Although certain articles seem to shed some light on the subject, since they are invoked in some differences of the total accumulated to date, such as "Article VIII Fees and Formalities connected with Importation and Exportation" and "Article XI General 
Elimination of Quantitative Restrictions", among others; in short, the WTO fails to remedy this situation. Therefore it is crucial within the multilateral trading system to conduct a new negotiation process in which a definitive agreement is developed to regulate this type of trade policies.

Key words: Reverse protectionism. Export restraint. Multilateral trading system. GATT. WTO.

\section{RESUMO}

Desde a criação da OMC, algumas demandas foram recebidas de seus Estados membros, todas com relação à adoção de restrições à exportação. Essa prática envolve a configuração de um novo tipo de protecionismo chamado "protecionismo reverso", que não parece ser totalmente regulado pelas disposições do GATT. Embora alguns de seus artigos pareçam lançar alguma luz sobre o assunto, eles foram invocados em algumas das diferenças existentes até o momento - como "Artigo VIII - Direitos e Formalidades relativas à importação e exportação" e "Artigo XI Eliminação Geral de Restrições Quantitativas", entre outros - a incapacidade do GATT e da OMC para remediar esta situação é evidente. Portanto, dada essa falta, é crucial, dentro do sistema multilateral de comércio, que um novo processo de negociação seja conduzido, no qual um acordo definitivo que regulamente esse tipo de política comercial seja desenvolvido.

Palavras-chave: Protecionismo inverso. Restrições à exportação. Sistema de negociação multilateral. GATT. OMC.

Introducción

A mediados de los noventa, tras el fin de la Ronda Uruguay en 1994, se alcanzaron importantes avances dentro del sistema multilateral de comercio haciendo posible el desarrollo de la mayoría de textos jurídicos en materia de comercio, muchos de estos aún vigentes. Dichos textos constituyen una especie de acuerdo marco en donde se incluyen como anexos los acuerdos relativos a las mercancías, los servicios, la propiedad intelectual, la solución de diferencias, el mecanismo de examen de las políticas comerciales y los acuerdos plurilaterales. Desde aquel entonces, muchos de estos acuerdos han permitido complementar significativamente el ordenamiento jurídico y las regulaciones del General Agreement on Tariff and Trade (GATT) o Acuerdo General sobre Aranceles Aduaneros y Comercio, el cual, como consecuencia de la creación de todas estas nuevas disposiciones, experimentó una importante enmienda (NARLIKAR; DAUNTON; STERN, 2012).

Otro importante avance fue precisamente la celebración del acuerdo de Marrakech en 1995, que daría origen a la Organización Mundial del Comercio (OMC), la cual desde aquel entonces ha promovido, entre otras cosas, el desarrollo de políticas económicas y liberalización del comercio a escala mundial. De las actuaciones de la OMC destacan: en primer lugar, la facilitación de negociaciones comerciales, que incluyen mercancías, servicios y propiedad intelectual. En segundo lugar, velar por la aplicación de sus acuerdos desarrollados principalmente el régimen del GATT. Dichos acuerdos obligan a los gobiernos a garantizar la transparencia de sus políticas comerciales, así como informar a la OMC 
sobre las leyes en vigor y las medidas adoptadas. En tercer y último lugar, la constitución del procedimiento de resolución de reclamaciones ante el Órgano de Solución de Diferencias (OSD), que sirve para gestionar las controversias entre miembros, y que resulta vital para la observancia de las normas, y en consecuencia para hacer posible la fluidez de los intercambios comerciales entre los países miembros (MARCEAU, 2015; CARDONA, 2018).

Sobre el OSD es importante agregar precisamente que este es el sistema empleado por los estados cuando se está infringiendo un acuerdo o un compromiso en el marco de la OMC; y es ante tal instancia en donde se han venido recibiendo demandas por parte de los estados miembros de pleno derecho. Lo anterior, teniendo en cuenta que tales demandas judiciales o diferencias tienen que ver con la implementación de políticas comerciales alusivas a restricciones a las exportaciones; por un lado, como barreras arancelarias (BA) y por otro lado, como barreras no arancelarias (BNA).

Toda esta situación supone entonces, el auge de nuevas controversias relacionadas con políticas comerciales puntuales que para este caso serán denominadas como proteccionismo inverso o neoproteccionismo de exportación dado su infrecuente uso además de su modus operandi dentro del comercio internacional. Asimismo supone, una carencia en la normativa actual dado que las BA y BNA para la exportación parecen no estar reguladas a cabalidad por las disposiciones de los textos legales del GATT (TORRES, 2013); todo esto, aparte de diversos asuntos por resolver relacionados con la toma de decisiones entre los miembros, la falta de voluntad política y las dificultades referidas a consenso las cuales se tornan en el presente bastante problemáticas (NELSON, 2015).

Tan complejo se torna todo este tema que la OMC ha venido solicitando nuevos compromisos para los nuevos miembros en sus protocolos de adhesión; además, de que los mismos países están acordando cláusulas especiales en sus acuerdos comerciales para prohibir o regular las restricciones a la exportación (KORINEK; BARTOS, 2012; HUANG, 2012). Lo anterior como una medida y/o política comercial internacional paralela a las normas del sistema multilateral de comercio contenidas en las disposiciones del GATT aparte de la normativa de los textos jurídicos, todas estas, administradas por la OMC (KARAPINAR, 2011; ANANIA, 2013; BAENA, 2016).

En este sentido dentro de este artículo se presenta el marco teórico de toda esta investigación en cuyo caso se reflexiona en torno a lo sui generis de las restricciones a la exportación de mercancías dentro del comercio internacional. Sucesivamente se expone también la metodología en donde se consultan las bases de datos de la OMC sobre temas comerciales y son identificadas todas las diferencias por orden cronológico planteadas hasta la fecha sobre las BNA y las BA aplicadas a la exportación de mercancías, como también algunos aspectos alusivos al tema central e incluso respecto a la posición política de los países protagonistas.

Igualmente sobre los resultados, el artículo muestra cifras relacionadas con las diferencias existentes en la actualidad, el total de restriccio- 
nes aplicadas a la exportación, los países que emplean este tipo de mecanismos, entre otros aspectos más. Sucesivamente, en apartado final, son planteadas las conclusiones en cuyo caso se reconoce la necesidad de que la OMC trabaje en la creación e implementación de políticas comerciales claras que regulen adecuadamente todo este tema que parece tomar cada vez más relevancia dentro del comercio internacional.

El papel del sistema multilateral de comercio para el desarrollo de políticas comerciales

Después del final de la Segunda Guerra Mundial, toda la iniciativa del GATT para promover el libre comercio entre los estados tuvo en su momento el propósito de construir y mejorar el sistema de comercio internacional; todo ello, por medio de la concertación de reglas a través de un acuerdo que permitiera la definición e implementación de medidas de política comercial. El GATT buscó igualmente alcanzar algunos compromisos como la reducción de los aranceles aduaneros y las barreras comerciales para mantener los mercados abiertos e incluso establecer los procedimientos aplicables para la resolución de disputas (MARCEAU, 2015).

Asimismo en el seno de esta iniciativa fueron llevadas a cabo las denominadas rondas comerciales del GATT, las cuales han sido la clave para encontrar soluciones en torno al tema de la creación de políticas y disposiciones normativas comunes para los países dentro del comercio internacional. Es en este sentido que muchas cuestiones discutidas en estas reuniones, las cuales alcanzaron un total de ocho rondas a lo largo de casi cinco décadas, fueron llevadas a cabo por los mismos países contratantes del GATT, y terminaron proporcionando finalmente algunas reglas necesarias para regular el comercio mundial el cual carecía de un ordenamiento jurídico concreto (PIEROLA, 2007).

Por lo tanto, está claro que la configuración del sistema multilateral de comercio, como se lo conoce hoy, ha sido resultado de un proceso arduo el cual comenzó en 1947 con la aprobación exitosa de la Carta de La Habana, que también incluía la creación de una figura conocida, en ese entonces, como la Organización Internacional de Comercio (OIC). Así este proyecto se intentaba concebir como una institución internacional para la regulación del comercio entre las partes contratantes del GATT; sin embargo, esta propuesta finalmente fracasó debido a la falta de aprobación del Congreso de los Estados Unidos como también a la falta de voluntad política entre las partes, una situación que sin dudas representó un gran revés para los inicios del sistema multilateral de comercio dada la ausencia de Estados Unidos como líder mundial a nivel económico (REIS, 2009).

Pues bien, según todo lo anterior, es posible afirmar que la OIC tenía la intención de completar la estructura de Bretton Woods de las instituciones económicas internacionales junto con el Fondo Monetario Internacional (FMI) y el Banco Mundial; no obstante, su caída dejó una brecha notable en esa estructura considerada una institución muerta, motivo por el cual toda esta propuesta finalmente fue reemplazada y administrada a 
través del GATT hasta la creación misma de la OMC muchos años más tarde (VAN DEN BOSSCHE; ZDOUC, 2013).

En este sentido, el proceso de construcción del sistema multilateral de comercio no ha sido un proceso para nada fácil, todo esto debido a que los países han tenido entonces que negociar en la mayoría de tales rondas, véase el Cuadro 1, diversos temas; entre los cuales siempre destacaron las reducciones arancelarias que eran a su vez el tema principal cubierto en la agenda del GATT. Aunque en las últimas tres rondas, justo antes del comienzo de la OMC, entre los temas más relevantes se incluyeron medidas no arancelarias, normas, servicios, propiedad intelectual, solución de diferencias, textiles, agricultura entre otros más. De hecho, sobre las medidas no arancelarias, las partes contratantes del GATT reconocieron un ajuste muy importante sobre las actitudes de las medidas comerciales a nivel político (HOWSE, 1998).

Cuadro 1- Rondas de negociación dentro del régimen del GATT y la OMC "incluyendo las conferencias ministeriales previas a Doha"

\begin{tabular}{|c|c|c|c|c|}
\hline Año & Denominación & Temas abordados & Régimen & $\begin{array}{l}\text { Países } \\
\text { participantes }\end{array}$ \\
\hline 1947 & Ginebra & BA & GATT & 23 \\
\hline 1949 & Annecy & BA & GATT & 13 \\
\hline 1951 & Torquay & $\mathrm{BA}$ & GATT & 38 \\
\hline 1956 & Ginebra & $\mathrm{BA}$ & GATT & 26 \\
\hline $1960-1961$ & Ginebra (Ronda Dillon) & $\mathrm{BA}$ & GATT & 26 \\
\hline $1964-1967$ & Ginebra (Ronda Kennedy) & BA y medidas antidumping & GATT & 62 \\
\hline $1973-1979$ & Ginebra (Ronda de Tokio) & BA, BNA y acuerdos relativos al marco jurídico & GATT & 102 \\
\hline $1986-1994$ & Ginebra (Ronda Uruguay) & $\begin{array}{l}\text { BA, BNA, normas, servicios, propiedad intelectual, solución de difer- } \\
\text { encias, textiles, agricultura, creación de la OMC, entre otros. }\end{array}$ & GATT & 123 \\
\hline 1996 & Conferencia Ministerial de Singapur & $\begin{array}{l}\text { Inversiones, política de competencia, contratación pública y facil- } \\
\text { itación del comercio. }\end{array}$ & OMC & 128 \\
\hline 1998 & Conferencia Ministerial de Ginebra & Comercio electrónico, entre otros. & OMC & 132 \\
\hline 1999 & Conferencia Ministerial de Seattle & $\begin{array}{l}\text { Comercio electrónico, subvenciones a la pesca, comercio y medio am- } \\
\text { biente y desarrollo sostenible, obstáculos técnicos al comercio, aspec- } \\
\text { tos de los derechos de propiedad intelectual, adhesiones, entre otros. }\end{array}$ & OMC & 135 \\
\hline 2001 & Ronda de Doha & $\begin{array}{l}\text { Agricultura, servicios, acceso a los mercados para los productos no } \\
\text { agrícolas, aspectos de los derechos de propiedad intelectual rela- } \\
\text { cionados con el comercio, relación entre comercio e inversiones, } \\
\text { interacción entre comercio y política de competencia, transparencia } \\
\text { de la contratación pública, facilitación del comercio, antidumping, } \\
\text { subvenciones, acuerdos comerciales regionales, entendimiento } \\
\text { sobre solución de diferencias, comercio y medio ambiente, miem- } \\
\text { bros de reciente adhesión, ayuda para el comercio, trato especial y } \\
\text { diferenciado, entre otros. }\end{array}$ & OMC & 157 \\
\hline
\end{tabular}

Fuente: Elaboración propia con datos de OMC (2017) y Silva (2001).

Consecuentemente tras ser efectuadas tres conferencias ministeriales en el marco de la OMC, algunas de estas con notables dificultades considerando la multiplicidad de asuntos por resolver y los retos asociado a voluntad política entre las partes (ODELL, 2009), finalmente en la cuarta Conferencia Ministerial se alcanza la primera y la más reciente ronda de negociación denominada la Ronda de Doha; cuyo objetivo propendía por alcanzar una importante reforma del sistema de comercio internacional a través del establecimiento de medidas encaminadas a reducir los obstáculos al comercio. Esto además de revisar diversas normas comerciales en 
donde se intentaron abordar unas 20 esferas del comercio; todo esto, en un momento estratégico para el sistema multilateral de comercio dada la adhesión oficial de la República Popular China comprendido como el país más grande que alguna vez haya hecho parte de la OMC y que incluso, hasta la fecha, ha venido generando cambios importantes en la dinámica del sistema multilateral de comercio (GAO, 2015) (ORGANIZACIÓN MUNDIAL DEL COMERCIO, 2017b).

Ahora bien, cabe anotar entonces que en la actualidad las Conferencias Ministeriales de la OMC siguen adelante ya que después de la oficialización de Doha, como Ronda de negociación, las reuniones periódicas se han venido manteniendo con una nueva conferencia en Cancún 2003, Hong Kong 2005, dos nuevas más en Ginebra 2009 y Ginebra 2011, Bali 2013, Nairobi 2015 y la más reciente Buenos Aires 2017. Alcanzándose así, con esta última, la undécima conferencia programada en donde se esperan seguir discutiendo nuevos temas e incluso adoptando nuevas decisiones en materia de comercio (ORGANIZACIÓN MUNDIAL DEL COMERCIO, 2017a).

De este modo, tras la creación de la OMC se ha promovido entonces la aplicación diversas normas e instrumentos jurídicos los cuales incluso se intentan mejorar con el desarrollo de las conferencias ministeriales; las cuales son consideradas eje central para la toma de decisiones en el sistema multilateral de comercio. En este sentido, se puede decir entonces que todas estas normas han presidido un importante periodo en el cual se han registrado algunas de las mayores tasas de crecimiento del comercio internacional; ya que estas disposiciones han venido impulsando la cooperación y el desarrollo entre todos los miembros de pleno derecho de la OMC (MINDREAU, 2005; ORGANIZACIÓN MUNDIAL DEL COMERCIO, 2017).

Así pues, se puede agregar también que el funcionamiento mismo del sistema multilateral de comercio depende de la confianza entre los países miembros, de hecho, este aspecto es determinante; ya que se hace imprescindible que los miembros de pleno derecho de la OMC perciban confianza y beneficio mutuo en un ambiente de reciprocidad en donde puedan ser además atendidos asuntos puntuales como son por ejemplo, su estructura básica, del desarrollo de normas, la aplicación misma de las normas como también la participación de los miembros en la toma de decisiones (LAL-DAS, 2004).

$Y$ aunque si bien existen diversos estudios que resaltan la trascendencia de la soberanía en los estados, el papel del sistema multilateral de comercio, la incidencia misma de la OMC, como incluso el rol de algunos otros organismos más similares; los caules se tornan imprescindibles para afianzar la liberalización y promover el crecimiento del comercio internacional dentro del contexto de la globalización (GRABENDORFF, 2005; FERNÁNDEZ, 2009; CARDONA, 2017). Es válido exaltar que también existen trabajos donde se han analizado, con datos secundarios, la incidencia del actual sistema de comercio internacional sobre la liberalización del comercio internacional. En este sentido, los resultados parecen cuestionar seriamente, por un lado, si realmente las políticas de la OMC han liberalizado el comercio del modo más 
apropiado para las economías de sus países miembros (ROSE, 2004); o si incluso, de otro lado, existen desequilibrios normativos sustanciales en la misma toma de decisiones dentro de tal sistema como también de otros tantos asuntos más que evidentemente tienen que ser superados como por ejemplo los resultados de la Ronda de Doha (KHOR, 2003; HELD, 2007).

En cualquier caso, pese a las críticas que puedan suscitarse en torno al rol del sistema multilateral de comercio Subramanian y Wei (2007) sostienen que aunque el crecimiento de los países miembros de la OMC ha sido desigual, esta generado un impacto relevante en el comercio internacional; ya que los datos sugieren un importante aumento total del volumen de las importaciones y las exportaciones de los países. Esto ha significado en consecuencia un crecimiento de más de 8 billones de dólares, es decir, aproximadamente un incremento del 120\% del comercio mundial adicional respecto décadas anteriores.

No caben dudas entonces, que pese a las dificultades de la OMC, el FMI, el Banco Mundial y otras tantas instituciones internacionales que participan directa e indirectamente dentro del sistema multilateral de comercio; todos estos organismos han hecho posible gestionar, de alguna manera, el devenir de la misma globalización como fenómeno social. Por ello es posible agregar que "[...] sin mercados globales, las economías centrales estarían abocadas al debilitamiento y la extinción, y -lo que suele pasarse por alto- y de este modo arrastrarían en su caída a las economías del resto del mundo" (RESTREPO, 2005). También según Baldwin (2016) la gran mayoría de objetivos del sistema multilateral de comercio se han logrado cumplir, ya que ha sido posible afianzar la OMC como paradigma comercial basado en normas que son universalmente aceptadas y respetadas entre todos sus miembros. Asimismo ha sido posible que las BA o medidas arancelarias hayan disminuido a niveles promedio históricos; aparte de que ha sido posible también reducir enormemente las BNA a la inversión, al comercio de mercancías y al comercio de servicios. Lo anterior, pese a que la última y única ronda de negociación de la OMC, la Ronda de Doha, ha experimentado importantes reveses y fracasos desde su lanzamiento en 2001.

Así todos estos nuevos cambios en las sociedades, condicionados por la dinámica misma de la globalización además de la configuración del sistema multilateral de comercio, han terminado por dar acceso muchos mercados que anteriormente estaban aislados; una situación en la que ha sido posible entonces que las fronteras políticas se vuelven cada vez más irrelevantes y en donde muchos países en desarrollo han tenido éxito en el propósito de lograr un mayor crecimiento económico aspirando a desempeñar un papel más importante en las negociaciones internacionales. Aunque pese a todo, es evidente que el mismo sistema internacional intenta corregir diversos problemas a fin de garantizar un mayor acceso a los bienes públicos mundiales, además de prevenir los efectos asimétricos ocasionados por fallos del mercado; y es por ello que en el ámbito social el desafío de superar los notables problemas de pobreza siguen siendo un compromiso político para todos los países que participan dentro de todo este proceso de gobernanza global (PERE, 2005). 
Contextualización sobre las restricciones a la exportación dentro del comercio internacional

Históricamente el proteccionismo ha sido entendido como una política comercial desarrollada e implementada por los gobiernos centrales, en cuyo caso son implementadas diversas medidas y/o restricciones expresadas tanto BA como BNA. Todo lo anterior, con el propósito de restringir el ingreso e incluso la salida de mercancías en un lugar específico y fin de garantizar ciertos intereses particulares de un Estado (BAENA, 2018); intereses los cuales por lo general suelen responder a objetivos propios de seguridad nacional (BERNITZ; RINGE, 2010).

Igualmente es necesario agregar que pese a los notables esfuerzos del sistema multilateral de comercio por promover la no implementación de políticas proteccionistas desmesuradas por parte de los estados miembros de la OMC; lo cierto es, que muchas medidas de esta naturaleza como los impuestos aduaneros, las cuotas y/o restricciones cuantitativas, las salvaguardias y muchas otras tantas. Suelen ser en últimas un recurso bastante común especialmente en periodos de crisis en donde los países tienden a verse tentados por recurrir a este tipo de mecanismos restrictivos motivados, en muchos casos, por la misma incertidumbre del entorno económico (BAENA; MONTOYA; TORRES, 2017).

Sobre el caso de las BA o medidas arancelarias es importante agregar que todas estas, expresadas exclusivamente en impuestos aduaneros, fueron posiblemente el recurso tradicionalmente más común para restringir el comercio dado que su implementación data desde la antigüedad misma; además de que todas estas han constituido una fuente de ingresos sumamente importante para los gobiernos centrales, considerando la versatilidad que estas ofrecen al ser aplicados impuestos aduaneros sobre los productos que se importan e incluso exportan (ASAKURA, 2003). De hecho, es quizás esa misma versatilidad la que permitió que muchos siglos después esta medida se convirtiera en la base del proteccionismo moderno, ya que las BA y/o impuestos aduaneros adoptaron una función estratégica dentro de las economías, en cuyo caso los precios extranjeros, y por lo general más bajos, tendían a ser nivelados discrecionalmente en relación a los precios de los productos nacionales. Aspecto el cual termina por otorgar una clara ventaja dentro del comercio internacional para todas aquellas empresas nacionales con problemas de productividad (BALLESTEROS, 2001; TUGORES, 2002).

De igual modo, con la configuración del sistema multilateral de comercio, precedido GATT y la misma OMC, se han desarrollado políticas comerciales que han propendido de manera ardua en liberalizar cada vez más el comercio. Disminuyendo puntualmente las BA y/o impuestos aduaneros dado que fueron justamente estas medidas las que más condicionaron, a nivel histórico, todo el devenir del comercio internacional; de hecho, fueron precisamente estas medidas, véase el Cuadro 1, las que protagonizaron siempre el tema de fondo dentro el desarrollo de las rondas de negociación en el viejo régimen del GATT (BAENA; FERNÁNDEZ, 2016; BAENA, 2019). 
De otro lado, en el caso de las BNA o medidas no arancelarias es también preciso señalar que estas, expresadas en una gran multiplicidad de mecanismos distintos a los impuestos aduaneros, son posiblemente el recurso más común dentro del proteccionismo en la actualidad; dado que los impuestos aduaneros y/o aranceles se encuentran significativamente controlados debido al papel ejercido por las disposiciones del GATT y el papel activo de la OMC. En cualquier caso, estas medidas no arancelarias también han adoptado una función estratégica dentro de las economías, ya que los gobiernos centrales pueden circunscribir de un modo más tajante los flujos comerciales tanto de entrada como de salida permitiéndoles así corregir con mayor rapidez ciertas situaciones indeseadas en los mercados. Esto sin nivelar los precios de tales flujos sino, concretamente, limitando las cantidades de las mercancias, lo cual también puede redundar en una clara ventaja para ciertas empresas locales (LEVY, 2003).

Cabe igualmente anotar que la condición de popularidad, referida con antelación, también puede explicarse en buena parte por el hecho de que los gobiernos tiendan cada vez más a desarrollar directrices que se aplican sobre los flujos comerciales de entrada y/o importaciones, e incluso sobre los flujos comerciales de salida y/o exportaciones, buscando alcanzar objetivos determinados en materia de inocuidad; y que de manera suspicaz pueden llegar, en ciertos casos, a ser solicitados de manera excesiva configurándose en este sentido una protección encubierta al comercio (ORGANIZACIÓN MUNDIAL DEL COMERCIO, 2010).

Parecen resultar entonces claros los propósitos tanto de las BA como de las BNA dentro de la lógica del proteccionismo convencional; no obstante, el comercio mundial está siendo testigo de nuevas prácticas comerciales llevadas a cabo por parte de algunos estados, en cuyo caso están siendo implementadas, de una manera distinta, estas medidas arancelarias y no arancelarias concretamente a través de restricciones a la exportación de mercancías y recursos. Todo ello, en un escenario de profunda complejidad para el sistema multilateral de comercio dada la ausencia de una regulación cabal al respecto además de los retos que puede implicar a nivel político en la OMC dentro de la agenda de las conferencias ministeriales, o en su defecto en una nueva posible ronda de negociación, abordar este nuevo tema (KARAPINAR, 2011; ANANIA, 2013; BAENA, 2016).

Según lo anterior, las restricciones a la exportación están siendo aplicadas por diversas razones que pueden responder a objetivos políticos tales como la seguridad nacional y la protección del medio ambiente además de otras metas sociales más amplias y complejas. No obstante, es evidente también que este tipo de políticas comerciales, véase el Cuadro 2 , responden a objetivos económicos tales como el aumento de los ingresos públicos, la promoción de las industrias transformadoras, la diversificación de las exportaciones, el control de las fluctuaciones de precios entre otras metas más (MILDNER; LAUSTER, 2011). 
Cuadro 2- Razones económicas que motivan el uso de BA y BNA en la exportación

\begin{tabular}{|c|c|}
\hline Caso BA o Medidas Acancelarias & Razones \\
\hline La mejora de los términos de intercambio & $\begin{array}{l}\text { Al restringir las exportaciones, un país que suministra una importante cuota del mercado mundial puede } \\
\text { elevar su precio mundial. Esto implica una mejora de sus términos de intercambio, lo que permite que el } \\
\text { país importador termine pagando más por cada unidad de la mercancía exportada. }\end{array}$ \\
\hline $\begin{array}{l}\text { La seguridad alimentaria y la estabilización } \\
\text { del precio final de consumo }\end{array}$ & $\begin{array}{l}\text { Al crearse una brecha entre el precio mundial y el precio interno, los impuestos a las exportaciones redu- } \\
\text { cen este último mediante la reorientación de la oferta nacional hacia el mercado interno. De hecho, hay } \\
\text { algunos ejemplos en los que el gobierno de Indonesia que imponen impuestos a la exportación de produc- } \\
\text { tos de aceite de palma, incluyendo crudo y de palma de aceite de cocina en 1994, ya que considera que el } \\
\text { aceite de cocina como un producto "esencial". Durante la crisis alimentaria de } 2006-2008 \text {, esta fue la prin- } \\
\text { cipal motivación para varios gobiernos a aplicar impuestos a la exportación y otras formas de restricciones } \\
\text { a la exportación. }\end{array}$ \\
\hline $\begin{array}{l}\text { La estabilización de los precios de con- } \\
\text { sumo intermedios y el desarrollo de indus- } \\
\text { trias de transformación }\end{array}$ & $\begin{array}{l}\text { Los impuestos a la exportación de productos primarios (en especial los no procesados) funcionan como } \\
\text { subsidio para la mayoría de industrias de procesamiento de valor añadido, ya que esta medida promueve } \\
\text { el suministro y garantiza la reducción de los precios internos en los insumos en comparación con el } \\
\text { precio mundial. }\end{array}$ \\
\hline El aumento de los ingresos públicos & $\begin{array}{l}\text { Los impuestos a la exportación proporcionan ingresos a los países en desarrollo, sobre todo cuando existe } \\
\text { una capacidad limitada que depender de la tributación interna. }\end{array}$ \\
\hline La redistribución del ingreso & $\begin{array}{l}\text { Al igual que los gravámenes de importación, los aranceles a la exportación son medidas que implican la } \\
\text { redistribución de los ingresos: los impuestos de exportación se aplican en detrimento de los productores } \\
\text { nacionales y en favor de los consumidores nacionales y de los ingresos públicos, mientras que los aranceles } \\
\text { de importación son perjudiciales para los consumidores domésticos, pero benefician a los productores } \\
\text { nacionales y los ingresos públicos. }\end{array}$ \\
\hline $\begin{array}{l}\text { La estabilización de los ingresos de ex- } \\
\text { portación }\end{array}$ & $\begin{array}{l}\text { Con el fin de estabilizar los precios internos y los ingresos de exportación para los productores que ex- } \\
\text { portan, algunos países en desarrollo aplican tasas impositivas altas además de tasas variables cuando los } \\
\text { precios de exportación son superiores a los precios de las mercancías nacionales y tasas o impuestos bajas } \\
\text { en el caso contrario. }\end{array}$ \\
\hline Caso BNA o Medidas No Acancelarias & Razones \\
\hline $\begin{array}{l}\text { Proteger y promover las industrias nacio- } \\
\text { nales de procesamiento y/o transformado- } \\
\text { ras con materias primas e insumos baratos. }\end{array}$ & $\begin{array}{l}\text { Esta política conlleva al mismo resultado tanto haciendo uso de BNA como de BA, ya que ambas medidas } \\
\text { se categorizan como restricciones a la exportación. Así que tanto las restricciones cuantitativas como los } \\
\text { derechos a la exportación terminan por proporcionar en últimas una ventaja importante a las industrias de } \\
\text { transformación que emplean como insumos materias primas para llevar a cabo bienes terminados }\end{array}$ \\
\hline $\begin{array}{l}\text { Promover políticas sociales como la pro- } \\
\text { tección del medio ambiente o la conser- } \\
\text { vación de los recursos naturales. }\end{array}$ & $\begin{array}{l}\text { Este es el objetivo político más popular para justificar una restricción cuantitativa a la exportación o incluso } \\
\text { una salvaguardia. Para la consecución de este propósito limitar el volumen de comercio de ciertos recursos } \\
\text { es un factor clave y por ello las restricciones cuantitativas suelen ser determinante para lograrlo; asimismo } \\
\text { en menor medida, los derechos de exportación también se utilizan para lograr estos objetivos políticos. }\end{array}$ \\
\hline $\begin{array}{l}\text { Control de las presiones inflacionarias y } \\
\text { asegurar el abastecimiento interno (espe- } \\
\text { cialmente con los productos agrícolas para } \\
\text { la seguridad alimentaria). }\end{array}$ & $\begin{array}{l}\text { Un aumento en el precio internacional de un producto puede crear presiones inflacionarias, por ello las } \\
\text { BNA pueden actuar como una medida para controlar la inflación, esto manteniendo los precios estables de } \\
\text { los productos básicos. Una restricción a la exportación, promueve el aumento de la oferta interna, reduce } \\
\text { el precio interno del producto, y por lo tanto compensando en parte las presiones inflacionarias provenien- } \\
\text { tes de los precios más altos en el extranjero. }\end{array}$ \\
\hline Contrarrestar la progresividad arancelaria. & $\begin{array}{l}\text { Las restricciones a la exportación pueden contrarrestar la progresividad arancelaria de los países impor- } \\
\text { tadores. Esta práctica consiste en cobrar BA de importación, más elevadas a los productos elaborados, } \\
\text { respecto a los no procesados. El uso de impuestos a la exportación fue sugerido por varios países como una } \\
\text { opción política para reducir el impacto de la progresividad arancelaria sobre sus exportaciones de produc- } \\
\text { tos procesados. }\end{array}$ \\
\hline
\end{tabular}

Fuente: Elaboración propia con datos de Bouet y Laborde (2010).

En este orden de ideas, una nueva clase de proteccionismo para la exportación de mercancías parece estar erigiéndose con fuerza; todo ello, además con una serie de efectos los cuales tienden a ser diferentes para las empresas y la industria nacional desde el paradigma mismo de intervención del Estado. Lo anterior, considerando el hecho de que en este caso se inmiscuye especialmente la seguridad nacional como un componente estratégico para el mismo funcionamiento político, aparte del económico, dado lo imperativo de garantizar el suministro interno de ciertas mercancías y recursos para evitar colapsar el sistema político social (ONO, 1984; ROMM, 1993; SOLLEDER, 2013).

Por lo tanto, según García (1996) tanto desde la perspectiva de la política económica como desde la perspectiva comercial se hace imprescindible, igualmente, una nueva lectura del mencionado fenómeno. Esto debido a la influencia de nuevas prácticas y procesos que en la actualidad 
destacan por su indudable peculiaridad; bien sea por la reconsideración neoproteccionista que suponen o bien sea por el carácter especialmente novedoso de su funcionalidad y modo de operar dentro la política comercial de los estados.

Las razones expuestas anteriormente, son pues motivos de peso por los cuales se puede argumentar que este tipo de políticas comerciales tienden a ser, por lo tanto, relativamente recientes dado que las restricciones a la exportación de mercancías no se llegaron a regular en su momento por el mismo GATT. Todo esto debido a la no necesidad de circunscribir este tipo de prácticas comerciales considerando lo infrecuente de su aplicación por parte de los países dentro del comercio internacional (LAMBERT; RUEFFER, 2010).

De este modo, se puede decir que dentro del sistema multilateral de comercio aún no se ha dado mayor relevancia a las restricciones a la exportación, al menos en términos jurídicos, pero llamativamente el tema toma cada vez más importancia dentro del comercio internacional; ya que las políticas proteccionistas de este tipo suelen responder a fenómenos profundamente relevantes que pueden estar cabalmente relacionados con la monopolización de recursos por parte de ciertos grupos de interés. Lo cual se puede reducir a la configuración de carteles económicos teniendo en cuenta la creciente la escasez producida por el agotamiento de los recursos (VALERO; VALERO, 2010; MATSUSHITA, 2011; BOLOTOVA, 2009).

No debe, por tanto, sorprender que en la actualidad ya se hayan hecho manifiestos diversos casos al respecto, en donde se especula en relación a todo este tema; todo ello, teniendo en cuenta la existencia de países con una disponibilidad sorprendente de recursos y que contemplan evidentemente políticas de esta naturaleza para manejar del modo más convenientemente posible tales recursos. Un ejemplo de todo lo anterior y precisamente el Estado más demandado ante el OSD es la República Popular China, véase el Cuadro 6, quien según estudios oficiales acumula aproximadamente el $97 \%$ de las tierras raras del planeta; recursos los cuales se han convertido en componentes esenciales para las industrias de alta tecnología y que podrían, a nivel político, erigir a este país hacia un nuevo liderazgo a nivel mundial (KIM; $\mathrm{KOH}$, 2012; HUMPHRIES, 2013).

De esta manera y considerando la tendencia en este neoproteccionismo que parece notarse cada vez más con el paso del tiempo, algunos trabajos e investigaciones han comenzado a categorizar el modo en que las medidas arancelarias y no arancelarias pueden ser en definitiva adoptadas por los gobiernos centrales como política comercial, véase el Cuadro 3, a fin de corregir situaciones concretas dentro de la economía interna (UNITED NATIONS CONFERENCE TRADE AND DEVELOPMENT, 2012; ORGANIZATION FOR ECONOMIC CO-OPERATION AND DEVELOPMENT, 2012). 
Cuadro 3- Clasificación de las restricciones a la exportación de BA y BNA

\begin{tabular}{|c|c|c|}
\hline Categoría BA & Descripción & Caso \\
\hline Derecho a la exportación & $\begin{array}{l}\text { Impuesto que se recauda sobre las mercancías o mate- } \\
\text { rias primas en el momento en que dejen un territorio } \\
\text { aduanero. }\end{array}$ & $\begin{array}{l}\text { Cuando se aplica un arancel para las mercancías que } \\
\text { son vendidas desde un país hacia cualquier otro país. }\end{array}$ \\
\hline Impuesto fiscal sobre las exportaciones & $\begin{array}{l}\text { Impuesto que no se paga en la frontera y que sólo se } \\
\text { aplica o discrimina bienes o productos destinados a la } \\
\text { exportación. }\end{array}$ & $\begin{array}{l}\text { Cuando los impuestos a las ventas que cobra el gobi- } \\
\text { erno son mayores para los bienes o materias primas } \\
\text { destinadas a la exportación, respecto a si se ofrecen } \\
\text { estos bienes o mercancías para la venta en el mercado } \\
\text { interno. }\end{array}$ \\
\hline Sobretasa de exportación & $\begin{array}{l}\text { Impuesto que se recauda sobre las mercancías en el } \\
\text { momento de salir del territorio aduanero, y que se } \\
\text { aplica, adicionalmente, a parte del arancel de export- } \\
\text { ación normal. }\end{array}$ & $\begin{array}{l}\text { Cuando se cobra un recargo de USD } 10 \text { por deter- } \\
\text { minado gobierno según la unidad de medida de la } \\
\text { mercancía exportada. }\end{array}$ \\
\hline $\begin{array}{l}\text { Referencia de los precios de Exportación/ } \\
\text { Precio minimo para las exportaciones }\end{array}$ & $\begin{array}{l}\text { Precio mínimo permisible para una mercancía que se } \\
\text { exporta; este puede ser empleado como una base para } \\
\text { calcular los impuestos a la exportación. }\end{array}$ & $\begin{array}{l}\text { Cuando se determina un precio mínimo de venta el } \\
\text { cual puede generar que aumente la base para el cobro } \\
\text { de gravámenes o incluso que los precios sean más } \\
\text { altos de lo que en teoría podrán ser vendidos. }\end{array}$ \\
\hline Impuesto temporal a la exportación & $\begin{array}{l}\text { Impuesto aplicado de manera momentánea, por lo } \\
\text { general durante menos de un año, con una fecha de } \\
\text { finalización definida. }\end{array}$ & $\begin{array}{l}\text { Cuando se implementa un arancel en un periodo } \\
\text { concreto a fin de corregir una situación puntual en la } \\
\text { economía interna. }\end{array}$ \\
\hline Categoría BNA & Descripción & Caso \\
\hline Salvaguardia & $\begin{array}{l}\text { Prohibición a la exportación de ciertos productos o } \\
\text { medida especial de urgencia. }\end{array}$ & $\begin{array}{l}\text { Cuando se aplica un arancel para las mercancías que } \\
\text { son vendidas desde un país hacia cualquier otro país. }\end{array}$ \\
\hline Cuotas & $\begin{array}{l}\text { Topes que limitan el valor o el volumen de las export- } \\
\text { aciones. }\end{array}$ & $\begin{array}{l}\text { Cuanto se aplica una restricción en las cantidades de } \\
\text { exportación que se establece para garantizar la oferta } \\
\text { adecuada en el mercado nacional. }\end{array}$ \\
\hline $\begin{array}{l}\text { Los requisitos de licencia o permisos para } \\
\text { exportar }\end{array}$ & $\begin{array}{l}\text { Requerimientos para obtener una aprobación o un } \\
\text { permiso del gobierno para exportar productos. }\end{array}$ & $\begin{array}{l}\text { Cuando las exportaciones de minerales pueden estar } \\
\text { sujetas a licencias de los gobiernos cuando son vendi- } \\
\text { dos a otro país. }\end{array}$ \\
\hline Sistema de precios duales & $\begin{array}{l}\text { Reglamentación donde se aplican diferentes precios } \\
\text { para un producto cuando se exporta y otro distinto } \\
\text { cuando se vende en el mercado interno. }\end{array}$ & $\begin{array}{l}\text { Cuando se aplican medidas que obligan a los provee- } \\
\text { dores de materias primas a venderlas a nivel interno } \\
\text { por debajo del precio que se debe vender la misma } \\
\text { mercancía en el exterior. }\end{array}$ \\
\hline $\begin{array}{l}\text { Restricción de despacho aduanero o punto } \\
\text { para las exportaciones }\end{array}$ & $\begin{array}{l}\text { El gobierno especifica los puertos y/o puntos de } \\
\text { acceso a través de los cuales las exportaciones deben } \\
\text { ser canalizadas o embarcadas. }\end{array}$ & $\begin{array}{l}\text { Cuando las exportaciones de mercancías de cierta } \\
\text { naturaleza deben de ser despachadas exclusivamente } \\
\text { desde ciertos puertos o lugares establecidos por el } \\
\text { gobierno. }\end{array}$ \\
\hline Obligación mercado nacional & $\begin{array}{l}\text { Acuerdo de una empresa frente al Estado, con la cual } \\
\text { se compromete una fracción de la producción anual } \\
\text { para el mercado nacional. }\end{array}$ & $\begin{array}{l}\text { Cuando la exportación de ciertos minerales solo se } \\
\text { puede llevar a cabo siempre y cuando una empresa } \\
\text { haya cumplido con un cupo de mercancía que se } \\
\text { destina para el mercado doméstico. }\end{array}$ \\
\hline Minería captiva & $\begin{array}{l}\text { Aprobación otorgada por el Estado para la ex- } \\
\text { plotación de minas con la intención de destinar la pro- } \\
\text { ducción exclusivamente hacia el mercado doméstico. }\end{array}$ & $\begin{array}{l}\text { Cuando el Estado otorga permisos a empresas que } \\
\text { explotan recursos para el consumo interno, todo ello } \\
\text { a fin controlar el precio y la disponibilidad de un pro- } \\
\text { ducto además de desincentivar las exportaciones. }\end{array}$ \\
\hline $\begin{array}{l}\text { Otras restricciones "No especificadas } \\
\text { previamente" }\end{array}$ & $\begin{array}{l}\text { Medidas que influyen de jure o de facto en el nivel o } \\
\text { la dirección de las exportaciones de bienes y materias } \\
\text { primas. }\end{array}$ & $\begin{array}{l}\text { Cuando el Estado emplea una multiplicidad de me- } \\
\text { canismos distintos para lograr el propósito de restrin- } \\
\text { gir las exportaciones. }\end{array}$ \\
\hline
\end{tabular}

Fuente: Elaboración propia con datos de UNITED NATIONS CONFERENCE TRADE AND DEVELOPMENT (2012) y ORGANIZATION FOR ECONOMIC CO-OPERATION AND DEVELOPMENT (2012).

Es evidente entonces que en los últimos años algunos estados, como la misma República Popular China e incluso Colombia -por citar algunos- en un intento quizás por conservar ciertos recursos estratégicos, han venido desarrollando políticas comerciales que en efecto intentan regular, a nivel interno, todo el tema de las restricciones a la exportación; situación que por lo tanto, evidencia una nueva dinámica y por ende la adopción de nuevos mecanismos que toman cada vez un mayor protagonismo dentro de los gobiernos centrales para restringir las exportaciones tanto con BA como con BNA dentro del comercio internacional 
(MINISTERIO DE COMERCIO CHINO, 2002; MINISTERIO DE COMERCIO INDUSTRIA Y TURISMO, 2016). De hecho en ciertos casos, dada la insuficiencia normativa de la misma OMC al respecto, diversos países han encontrado en la firma de acuerdos comerciales una opción bastante efectiva, hasta ahora, para prohibir o regular entre las partes implicadas este tipo de prácticas; generándose entonces una normativa y una serie de disposiciones paralelas al sistema multilateral de comercio (KORINEK; BARTOS, 2012; HUANG, 2012).

A la vista de lo anteriormente expuesto, cabe agregar que si bien los estados del sistema multilateral de comercio invocan ciertas normas del GATT o normas concretas de los textos jurídicos de la OMC cuando se han llegado a presentar demandas ante el OSD. Lo anterior, debido a que alguna de las partes considera que se están vulnerando sus derechos o porque determinadas políticas comerciales parecen menoscabar sus propias condiciones económicas y sociales; lo cierto es que infortunadamente estas normas parecen evidenciar vacíos bastante significativos que no logran regular a cabalidad el tema en cuanto a las restricciones a la exportación se refiere (LAMBERT; RUEFFER, 2010).

Respecto a lo anterior las normas de primera jerarquía más relacionadas con las restricciones a la exportación son en primera instancia, el artículo "XI Eliminación General de las Restricciones Cuantitativas" del GATT que exige a los miembros de la OMC que eliminen todas las prohibiciones y restricciones cuantitativas a las exportaciones, exceptuando aquellas de orden "temporal" para prevenir y aliviar la escasez de alimentos y productos "esenciales" o aquellas necesarias para la aplicación de reglamentos concretos referidos a control de calidad. Sin embargo, el artículo no es lo suficientemente específico como para definir las circunstancias puntuales en que se podrían justificar las políticas comerciales de esta naturaleza además de que este tampoco indica el alcance, la duración, el límite de las medidas restrictivas que podrían aplicarse aparte de no dejar claro los productos como tal que están sujetos a estas medidas (KARAPINAR, 2011).

En segunda instancia, el artículo "VIII Derechos y Formalidades referentes a la importación y a la exportación" del GATT el cual plantea que los aranceles, impuestos u otras cargas a las exportaciones "no deberán constituir un protección indirecta a los productos nacionales" pero para el caso de la exportación la implementación de estas medidas no suponen los mismos efectos que para el caso de la importación. Por lo tanto, el aspecto anterior parece tornarse impreciso además de que en este artículo no se prohíbe como tal el uso de medidas arancelarias, lo cual deja abierta diversas posibilidades para la aplicación de proteccionismo de este tipo (BAENA, 2016).

Cabe destacar también en el caso de las normas de segunda jerarquía que algo similar sucede con el artículo " 12 Disciplinas en materia de prohibiciones y restricciones a la exportación” del texto jurídico Acuerdo sobre la Agricultura (AsA) en donde los países que adopten este tipo de mecanismos deberán notificar al Comité de Agricultura de la OMC sobre la naturaleza y tiempo de tal restricción. Aunque en la práctica esta disposición complementaria al GATT tampoco ha generado los resultados 
esperados, básicamente, porque no todos los productos exportados que son susceptibles de ser restringidos son alimentos y además porque los acuerdos de la OMC -como el AsA entre otros tantos más que pudieran dar luces sobre las restricciones a la exportación pero que finalmente no lo hacen tampoco-, poseen una condición especial en lo que suele ser definido como "GATT à la carte"; ya que estos son solo vinculantes para aquellos estados signatarios que discrecionalmente hayan decidido incorporarlos en sus ordenamientos jurídicos (JACKSON, 2000).

En este mismo orden de ideas, si bien las medidas arancelarias a la exportación no han sido aún muy comunes entre los países; particularmente aquellos países menos desarrollados pueden considerar este mecanismo como una atractiva fuente de ingresos. Esto debido a que a nivel internacional la regulación para los aranceles no es igual de rígida para el caso de las exportaciones además de que a nivel interno puede resultar más conveniente incrementar los ingresos públicos por medio de impuestos aduaneros, sean de importación o de exportación, que haciendo uso de medidas políticamente más complejas como bien pueden ser los impuestos sobre la renta u otras cargas impositivas a los nacionales (MILDNER; LAUSTER, 2011).

$\mathrm{Y}$ es precisamente por el motivo anterior que de acuerdo a Ya Qin (2012) la OMC debería en definitiva aspirar a regular los derechos de exportación de la misma manera como lo ha alcanzado con los derechos de importación. Ya que en este último caso se ha logrado precisamente, como se estipula en el artículo "II Listas de concesiones" del GATT, que todos los estados miembros de la OMC se comprometan a fijar topes máximos de aranceles para cada producto en el caso de las importaciones; lo cual, a nivel jurídico permitiría superar en buena medida todo estos vacíos legales para el caso de los flujos comerciales de salida y/o exportaciones.

Finalmente si bien es cierto que las diferencias actuales sobre este tipo de proteccionismo se han logrado manejar a partir de la interpretación que efectúa el OSD con las normas actuales de primera y segunda jerarquía. Resulta tan evidente la complejidad de este tema sobre la regulación de las restricciones a la exportación; que dentro del sistema multilateral de comercio, en los últimos años, los países miembros de pleno derecho de la OMC han venido solicitando a los estados que se han venido sumando al organismo, determinados compromisos especiales en sus protocolos de adhesión; es decir, en los textos oficiales negociados para que estos últimos pasen a ser también miembros de pleno derecho. De este modo, por un lado, tales compromisos de los nuevos miembros, conocidos también como "OMC plus", tienden a tornarse en una norma adicional y totalmente sui generis dado que en estos se acuerdan disposiciones que no están circunscritas en el GATT y los textos jurídicos. Pero también, de otro lado, se tornan en una norma discriminatoria; ya que en estos son acordadas disposiciones especiales para regular las restricciones a la exportación, las cuales además han venido invocándose en las demandas presentadas ante el OSD, que no necesariamente son vinculantes para los miembros iniciales (YA QUIN, 2003; KORINEK; BARTOS, 2012; HUANG, 2012). 
Metodología

Con el propósito de contextualizar el presente tema objeto de estudio y asimismo identificar las principales diferencias dentro de la OMC en la primera parte de este artículo se efectúa un sólido marco teórico en cuyo caso fueron consultadas bases de datos de revistas de alto impacto científico como Web of Science (WOS) de Clarivate Analytics, Scopus de Elsevier entre otras bases de datos como Science Direct, Ebsco, Doaj, Scielo, y a fines, a través de las cuales fue posible identificar artículos, libros y ponencias cuyo criterio de búsqueda o palabras clave fueron principalmente "neoproteccionismo, restricciones a la exportación, sistema multilateral de comercio, GATT, OMC, entre otras", de igual modo es importante agregar también que esta terminología técnica fue también rastreada en inglés a razón de incrementar los resultados en el material bibliográfico de consulta.

Posteriormente, para la construcción de los resultados de este artículo científico se acudió a sitios web oficiales de organismos como la Organización Mundial del Comercio (OMC) en inglés World Trade Organization (WTO), también United Nations Conference on Trade and Development (UNCTAD), Global Trade Alert (GTA), la Organización para la Cooperación y el Desarrollo Económico (OCDE), el Ministerio de Comercio, Industria y Turismo, entre otras páginas más de la red que facilitaron el acceso a fuentes secundarias confiables, donde fue posible encontrar información y datos importantes para el desarrollo de los resultados. Información con la cual fue posible entonces exponer y describir el contenido central de esta investigación a través de cuadros y figuras que soportan el presente enfoque jurídico analítico completando efectivamente este apartado del artículo.

De este modo, teniendo en cuenta todo lo anterior, con todas estas bases de datos se llevó a cabo el presente estudio descriptivo sobre "el proteccionismo inverso y las restricciones a la exportación de mercancías" además de identificar las diferencias planteadas ante la OMC que hicieron posible en definitiva entender todo este fenómeno y responder así al tema central objeto de estudio del presente artículo de investigación.

Resultados

En función de todo lo planteado previamente, es preciso destacar entonces el papel de las diferencias planteadas dentro de la OMC sobre las restricciones a la exportación de mercancías, como también las disposiciones normativas inmiscuidas en las diferencias además de los países implicados y finalmente el proteccionismo inverso registrado en la actualidad respecto al proteccionismo total dentro del comercio internacional. Por lo tanto, en relación al primer aspecto, tras ser tenidas en cuenta todas las diferencias presentadas en el régimen del GATT y la actual OMC, véase la Figura 1, es posible determinar que desde los orígenes del sistema multilateral de comercio hasta la fecha, es decir en un periodo de siete décadas, se han registrado un total de 633 diferencias entre todos los países miembros de la OMC. 
Figura 1- Total de diferencias neoproteccionistas dentro del régimen del

GATT y la OMC

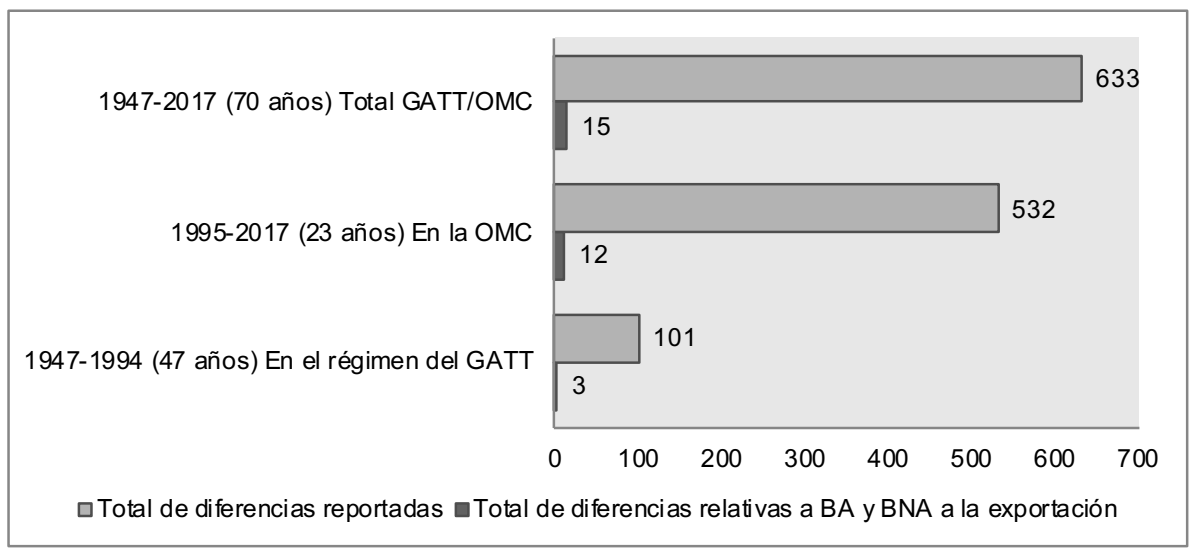

Fuente: Elaboración propia con datos de OMC (2017c) (2017d).

Cabe destacar que de todas estas únicamente 101 diferencias fueron llevadas a cabo en el viejo régimen del GATT, en cuyo caso se registraron puntualmente solo 3 diferencias relacionadas con proteccionismo inverso, es decir que tan solo un $2,97 \%$ de tales diferencias tuvieron que ver, entre el año 1947 y el año 1994, con restricciones a la exportación de mercancías. Mientras que de otro lado, de todas las 532 diferencias restantes que han sido llevadas a cabo dentro de la OMC, solo se han registrado 12 diferencias relacionadas con proteccionismo inverso. Es decir que para este último caso tan solo un $2,26 \%$ de tales diferencias han tenido que ver, entre el año 1995 y el año 2017, con restricciones a la exportación de mercancías.

De igual modo, si a nivel general si se analizara todo el contexto dentro del sistema multilateral de comercio; es decir un total de 633 diferencias, se habrían registrado entonces solo 15 diferencias, lo que significaría que tan solo $2,37 \%$ del total de diferencias, entre el año 1947 y el año 2017, estarían relacionadas con proteccionismo inverso o neoproteccionismo de exportación.

En relación al segundo caso, después de ser analizadas todas las diferencias presentadas en el régimen del GATT, se puede afirmar que desde los orígenes del sistema multilateral de comercio hasta el fin de la Ronda Uruguay, véase el Cuadro 4, las 3 diferencias que se presentaron fueron la BISDII/28 del 1949, la BISD35S/98 de 1986 y la BISD37S/200 de 1990.

Cuadro 4- Diferencias en el régimen de GATT de las políticas neoproteccionistas de tipo BNA

\begin{tabular}{|l|l|l|l|l|l|l|}
\hline $\begin{array}{l}\text { Nombre de la } \\
\text { diferencia }\end{array}$ & Año & $\begin{array}{l}\text { Tipo de Pro- } \\
\text { teccionismo }\end{array}$ & $\begin{array}{l}\text { Leyes } \\
\text { Invocadas }\end{array}$ & País Demandante & País Demandado & Recurso \\
\hline BISDII/28 & 1949 & BNA & Artículos I y XXI (GATT) & Checoslovaquia & Estados Unidos & Bienes en general \\
\hline BISD35S/98 & 1986 & BNA & Artículos XI y XX (GATT) & Estados Unidos & Canadá & Arenque y Salmón sin elaborar \\
\hline BISD37S/200 & 1990 & BNA & Artículo XI (GATT) & Estados Unidos & $\begin{array}{l}\text { Comisión Económica } \\
\text { Europea }\end{array}$ & Desechos de Cobre \\
\hline
\end{tabular}

Fuente: Elaboración propia con datos de OMC (2017d). 
Estas diferencias tuvieron que ver en su momento con bienes y mercancías en general, productos agrícolas de origen acuícola y materias primas minerales. Asimismo dentro de tales diferencias fueron invocados concretamente los artículos "I Trato general de la nación más favorecida", "XI Eliminación general de las restricciones cuantitativas", "XX Excepciones generales" y "XXI Excepciones relativas a la seguridad" del GATT; todo ello, destacando además que para este caso en particular ninguna de las 3 diferencias tuvo que ver con BA o medidas arancelarias.

$\mathrm{Y}$ precisamente, al analizarse las diferencias alusivas a BA o medidas arancelarias que se han presentado dentro de la OMC, véase el Cuadro 5, es posible determinar que las 8 diferencias que se presentaron fueron la DS394, la DS395, la DS398 del 2009, la DS431, la DS432, la DS433 del 2012 además de la DS508 y DS509 del 2016.

Cuadro 5- Diferencias dentro de la OMC de las políticas neoproteccionistas de tipo BA

\begin{tabular}{|c|c|c|c|c|c|c|}
\hline $\begin{array}{l}\text { Nombre de la } \\
\text { diferencia }\end{array}$ & Año & $\begin{array}{l}\text { Tipo de } \\
\text { Proteccionismo }\end{array}$ & $\begin{array}{l}\text { Leyes } \\
\text { Invocadas }\end{array}$ & País Demandante & País Demandado & Recurso \\
\hline DS394 & 2009 & $\mathrm{BA}$ & $\begin{array}{l}\text { Artículos VII, VIII, X y XI(GATT) } \\
\text { Protocolo de Adhesión. }\end{array}$ & Estados Unidos & China & Tierras raras \\
\hline DS395 & 2009 & $\mathrm{BA}$ & $\begin{array}{l}\text { Artículos VII, VIII, X y XI (GATT) } \\
\text { Protocolo de Adhesión. }\end{array}$ & Comunidades Europeas & China & Tierras raras \\
\hline DS398 & 2009 & $\mathrm{BA}$ & $\begin{array}{l}\text { Artículos VII, VIII, X y XI (GATT) } \\
\text { Protocolo de Adhesión. }\end{array}$ & México & China & Tierras raras \\
\hline DS431 & 2012 & $\mathrm{BA}$ & $\begin{array}{l}\text { Artículos VII, VIII, X y XI (GATT) } \\
\text { Protocolo de Adhesión. }\end{array}$ & Estados Unidos & China & Tierras raras \\
\hline DS432 & 2012 & $\mathrm{BA}$ & $\begin{array}{l}\text { Artículos VII, VIII, X y XI (GATT) } \\
\text { Protocolo de Adhesión. }\end{array}$ & Unión Europea & China & Tierras raras \\
\hline DS433 & 2012 & $\mathrm{BA}$ & $\begin{array}{l}\text { Artículos VII, VIII, X y XI (GATT) } \\
\text { Protocolo de Adhesión. }\end{array}$ & Japón & China & Tierras raras \\
\hline DS508 & 2016 & $\mathrm{BA}$ & $\begin{array}{l}\text { Artículos X y XI (GATT) Protocolo de } \\
\text { Adhesión. }\end{array}$ & Estados Unidos & China & Materias primas \\
\hline DS509 & 2016 & $\mathrm{BA}$ & $\begin{array}{l}\text { Artículos X y XI (GATT) Protocolo de } \\
\text { Adhesión. }\end{array}$ & Unión Europea & China & Materias primas \\
\hline
\end{tabular}

Fuente: Elaboración propia con datos de OMC (2017d).

Por lo tanto, es importante señalar que estas diferencias han tenido que ver principalmente con tierras raras y materias primas a fines; $y$ que además, particularmente, el país demandado en todas y cada una de las diferencias ha sido la República Popular China. También dentro de tales diferencias fueron invocados concretamente los artículos "VII Valoración en aduana", "VIII Derechos y formalidades referentes a la importación y a la exportación" y "XI Eliminación general de las restricciones cuantitativas" del GATT aparte de invocarse el Protocolo de Adhesión de la República Popular China en donde se establecieron compromisos adicionales al respecto.

Sobre las diferencias alusivas a BNA o medidas no arancelarias que se han presentado dentro de la OMC, véase el Cuadro 6, es posible hacer mención que las 4 diferencias que se presentaron fueron la DS107 de 1997, la DS120 y DS155 de 1998 y la DS194 del 2000. 
Cuadro 6- Diferencias dentro de la OMC de las políticas neoproteccionistas de tipo BNA

\begin{tabular}{|l|l|l|l|l|l|l|}
\hline $\begin{array}{l}\text { Nombre de la } \\
\text { diferencia }\end{array}$ & Año & $\begin{array}{l}\text { Tipo de Protec- } \\
\text { cionismo }\end{array}$ & $\begin{array}{l}\text { Leyes } \\
\text { Invocadas }\end{array}$ & $\begin{array}{l}\text { País Deman- } \\
\text { dante }\end{array}$ & País Demandado & Recurso \\
DS107 & 1997 & BNA & Artículos XI y XXIII (GATT) & Comunidades & Pakistán \\
\hline DS120 & 1998 & BNA & Artículos XI y XXIII (GATT) & $\begin{array}{l}\text { Comunidades } \\
\text { Europeas }\end{array}$ & India \\
\hline DS155 & 1998 & BNA & Artículos X y XI (GATT) & $\begin{array}{l}\text { Comunidades } \\
\text { Europeas }\end{array}$ & Argentina & Cueros y Pieles \\
\hline DS194 & 2000 & BNA & $\begin{array}{l}\text { Acuerdo SMC Artículos 1, 10, 11, 17,19 y } \\
\text { 32. Artículo XVI:4 Acuerdo de Marrakech }\end{array}$ & $\begin{array}{l}\text { Canadá } \\
\text { Estados Unidos }\end{array}$ & Bienes en general \\
\hline
\end{tabular}

Fuente: Elaboración propia con datos de OMC (2017d).

En este sentido se puede reconocer que estas diferencias han tenido que ver en su mayoría con curtiembres y mercancías en general; en donde fueron invocados concretamente los artículos "X Publicación y aplicación de los reglamentos comerciales", "XI Eliminación general de las restricciones cuantitativas" "XXIII Anulación o menoscabo" del GATT aparte de invocarse los artículos "1 Definición de subvención", "10 Aplicación del artículo VI del GATT de 1994", "11 Iniciación y procedimiento de la investigación", "17 Medidas provisionales", "19 Establecimiento y percepción de derechos compensatorios" y "32 Otras disposiciones finales" del Acuerdo sobre Subvenciones y Medidas Compensatorias (SMC) además del artículo "XVI:4 Disposiciones varias" del Acuerdo de Marrakech por el que se establece la OMC.

En relación al tercer y último caso, tras considerarse el proteccionismo inverso registrado en el presente, es posible determinar que todo éste en conjunto, véase la Figura 2, equivale tan solo a un 4,99\%; todo ello, respecto al proteccionismo convencional que alcanza un $95,01 \%$ de un total de más de 1200 BA y BNA de proteccionismo registrado dentro del comercio internacional hasta la fecha.

Figura 2- Neoproteccionismo de exportación total dentro del comercio internacional

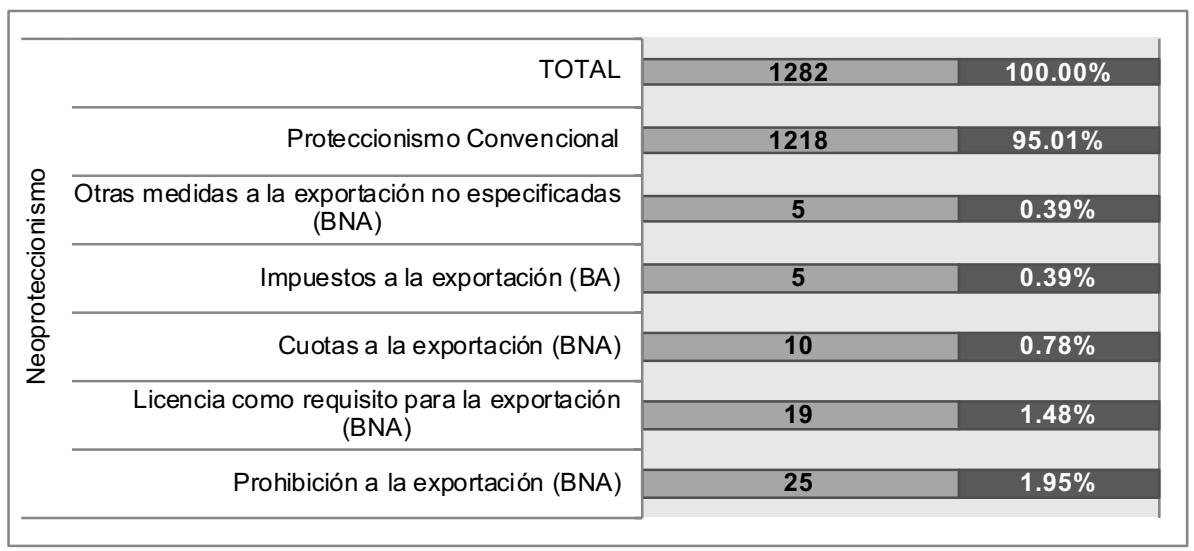

Fuente: Elaboración propia con datos de GLOBAL TRADE ALERT (2016).

Por consiguiente, tal y como se puede apreciar en la Figura 2, de un total de 64 medidas exclusivamente relacionadas con proteccionismo inverso, solo 5 de estas tienen que ver con BA o medidas arancelarias relativas con impuestos a la exportación, es decir tan solo un $0,39 \%$ del 
total del proteccionismo. Mientras que de las restantes de proteccionismo inverso 59 medidas tienen que ver con BNA o medidas no arancelarias, es decir un 4,60\% las cuales asimismo están repartidas en licencias como requisito para la exportación, cuotas a la exportación y otras medidas a la exportación no especificadas.

Conclusiones

Si bien el proteccionismo convencional, asociado en este caso a los flujos comerciales de entrada o importaciones, es considerablemente alto en la actualidad respecto al proteccionismo inverso, asociado a los flujos comerciales de salida o exportación, todo esto debido a que este último apenas comienza a manifestarse dentro del proteccionismo total empleado comercio internacional. Es altamente probable que con el agotamiento de los recursos en general tanto las BA como las BNA tiendan a aumentar con el tiempo dentro de los procesos de exportación de mercancías. De hecho en poco más de dos décadas, tras la creación de la OMC, se han cuadruplicado las demandas y/o diferencias alusivas a este tema ante el OSD; todas estas, en su mayoría contra la República Popular China, Estado que ha venido aplicando políticas comerciales restrictivas, presuntamente incompatibles con las normas del sistema multilateral de comercio, contra sus propias exportaciones en un intento por administrar a beneficio propio su producción de tierras raras y otros recursos estratégicos.

Por lo tanto, es crucial para el sistema multilateral de comercio que la OMC aborde todo este tema a fondo dentro del seno del máximo órgano de decisión; es decir, en las conferencias ministeriales o que incluso en su defecto se conduzca un nuevo proceso de negociación en el que se desarrolle un acuerdo detallado y pertinente sobre la regulación de las restricciones a la exportación. Todo esto considerando que estas políticas comerciales se han incrementado hoy en día, tal y como se ha podido demostrar, además de que las mismas diferencias al respecto, entre los estados miembros de la OMC, han venido en considerable ascenso en los últimos años ante el OSD. Diferencias en las cuales, por lo general, han sido invocados principalmente los artículos "VIII Derechos y Formalidades referentes a la importación y a la exportación" y el "XI: Eliminación General de las Restricciones Cuantitativas" del GATT e incluso los textos jurídicos; normas las cuales parecen no ser suficientes para regular a cabalidad el tema de las restricciones a la exportación, dado que los protocolos de adhesión -estos últimos aplicados exclusivamente a los nuevos miembros de la OMC- y la firma de acuerdos comerciales constituyen en el presente alternativas especiales y adicionales de regulación.

También resulta sumamente llamativo el hecho de que el proteccionismo inverso o neoproteccionismo de exportación tienda a acentuar algunas prácticas económicas que en la actualidad son bastante cuestionadas e inclusive censurables, en donde ciertos países intentan administrar sus propios recursos y materias primas en función de la disponibilidad de los mismos dentro del comercio internacional. Lo anterior, coordinando deliberadamente su producción y adoptando de este modo políticas co- 
merciales que inciden en su precio, tal y como sucede precisamente con la Organización de Países Exportadores de Petróleo (OPEP) y diversos hidrocarburos. Por lo tanto, esta situación puede suponer con el tiempo el escalonamiento de nuevos carteles entre determinados países que buscarían tener el control de ciertos recursos comunes, lo cual podría conllevar también al recrudecimiento de prácticas colusorias.

Sucesivamente todo este patrón de neoproteccionismo alusivo a restricciones a la exportación puede plantear, en definitiva, dentro de las relaciones internacionales todo un punto de inflexión para los estados que intentan seguir no solo las disposiciones del GATT y los textos jurídicos; sino también otros ordenamientos jurídicos del propio sistema internacional. Dado que si bien existe una gobernanza global dentro del paradigma actual de las relaciones internacionales, el agotamiento propio de los recursos y la sucesiva escasez puedan suponer una dinámica más compleja, y quizás sin precedentes, en donde se planteen escenarios de recusación de tales ordenamientos jurídicos debido a la imperatividad y primacía misma de la seguridad nacional como instinto de supervivencia política.

Referencias

ANANIA, G. Agricultural export restrictions and themWTO "What options do policy-makers have for promoting food Security?”. Programme on Agricultural Trade and Sustainable Development. 2013. Disponível em: <https://www.ictsd.org/downloads/2013/11/agriculturalexport-restrictions-and-the-wto-what-options-do-policy-makers.pdf>. Acesso em: 15 ago. 2018.

ASAKURA, H. World History of the Customs and Tariffs. Brussels: World Customs Organization. 2003.

BAENA, J. La política de comercio exterior y las exportaciones colombianas. Revista de Economía Institucional. vol. 21, n. 41, p. 51-70. 2019.

BAENA, J. Barreras arancelarias y no arancelarias como restricciones al comercio internacional. Revista Venezolana de Gerencia. vol. 23, n. 86, p. 543-562. 2018.

BAENA, J. Las restricciones y los aranceles a las exportaciones de mercancías en el Derecho de la OMC ¿barreras tradicionales o neoproteccionismo? Facultad de Derecho Universidad de Barcelona. 2016. Disponível em: <http://diposit.ub.edu/dspace/handle/2445/103722>. Acesso em: 29 set. 2018.

BAENA, J; FERNÁNDEZ, X. Aproximaciones a la inserción de Colombia en el sistema multilateral de comercio en 1995-2015. Análisis Político, vol. 29, n. 1, p.114-131. 2016.

BAENA, J; MONTOYA, A; TORRES, D. La crisis económica mundial ¿La proliferación del proteccionismo como una causa efecto? En-Contexto,vol. 5, n. 6 ,p. 185-207. 2017.

BALDWIN, R. The world trade organization and the future of multilateralism. Journal of Economic Perspectives, vol. 30, n. 1, p. 95-116. 2016.

BALLESTEROS, A. Comercio exterior teoría y práctica. Murcia, España: Editorial Universidad de Murcia. 2001.

BERNITZ, U., \& RINGE, W. Company Law and Economic Protectionism: New Challenges to European Integration. New York: Oxford University Press. 2010.

BOLOTOVA, Y. Cartel overcharges: An empirical analysis. Journal of Economic Behavior \& Organization, vol. 70, n. 1-2, p. 321-341. 2009.

BOUET, A; LABORDE, A. OECD Trade Policy Studies, The Economic Impact of Export Restrictions on Raw Materials. 2010. Organization for Economic Co-operation and Development. Disponível em: <http://www.oecd.org/publications/the-economic-impact-of-exportrestrictions-on-raw-materials-9789264096448-en.htm>. Acesso em: 05 nov. 2018.

CARDONA, G. Comercio Mundial tendencias y estructura. Medellín: Editorial CEIPA. 2017.

CARDONA, G. Integración Económica y Cooperación Internacional: entre el multilateralismo, el regionalismo y la supranacionalidad. Medellín: Editorial La Sallista. 2018. 
FERNÁNDEZ, X. Globalización económica, soberanía de los estados y políticas sociales: funciones y retos del derecho internacional ante el "Trilema" de la globalización. Sociedad Global revista de relaciones internacionales y ciencias políticas publicación de la Universidad Abierta Interamericana,vol. 3, n. 1, p. 43-84. 2009.

GAO, $\mathrm{H}$. From the doha round to the China round: China's growing role in WTO negotiations. En China in the International Economic Order: New Directions and Changing Paradigms. New York: Cambridge University Press. 2015.

GARCÍA, J. Neoproteccionismo, dumping social y eco-dumping. Nueva Sociedad, vol. 1, n. 143, p. 124-141.1996

GRABENDORFF, W. Relaciones triangulares en un mundo unipolar: América del Norte, la Unión Europea y América del Sur. Análisis Político,Vol. 38, n. 149, p. 3-19. 2005.

GLOBAL TRADE ALERT. 2016. Disponível em: < http://www.globaltradealert.org/global_dynamics/area_all/year-from_2016/year-to_2018>.Acesso em: 15 ago. 2018.

HELD, D. Redefinir la gobernabilidad global: ¡Apocalipsis cercano o reforma! Análisis Político, vol.1, n.62, p. 58-78.2007

HOWSE, R. The World Trading System: Critical perspectives on the World Economy. New York: Routledge. 1998.

HUANG, X. A Discussion on Exceptions to Export Restrictions Under GATT/WTO. Faculty of Law University of Oslo. 2012. D|isponível em: < https://www.duo.uio.no/bitstream/handle/10852/35645/axdiscussionxonxexceptionsxtoxexportxrestrictions_newxtemplate_XIAOQINGxHUANG.pdf?sequence=1>. Acesso em: 29 set. 2018.

HUMPHRIES, M. Rare Earth Elements: The Global Supply Chain. 2013. Congresional Research Service. Disponível em: <https://fas.org/sgp/crs/natsec/R41347.pdf>. Acesso em: 05 nov. 2018.

JACKSON, J. The Jurisprudence of GATT and the WTO: Insights on Treaty Law and Economic Relations. New York: Cambridge University Press. 2000.

KARAPINAR, B. Export Restrictions and the WTO Law: How to Reform the "Regulatory Deficiency". Journal of World Trade. vol. 45, n. 6, p.1139-1155. 2011

KHOR, M. ¿Qué hacemos con la OMC?: un programa de cambios para el comercio global. Barcelona: Icaria Editorial. 2003.

KIM, Y; KOH, J. The International Trade Legal Issues Surrounding China's Export Restraints on Rare Earths and the Prospects. Anam Law Review, p. 401-440. 2012.

KORINEK, J; BARTOS, J. Multilateralising regionalism: disciplines on export restrictions in regional trade agreements. Organisation for Economic Co-operation and Development. 2012. Disponnível em: <http://www.oecd.org/officialdocuments/publicdisplaydocumentpdf/?cote $=$ TAD $/$ TC $/ W P(2011) 23 /$ FINAL\&docLanguage $=$ En $>$. Acesso em: 17 ago. 2018.

LAL-DAS, B. La OMC y el sistema multilateral de comercio: pasado, presente y futuro. Barcelona, España: Icaria Editorial. 2004.

LAMBERT, J; RUEFFER, S. Legal memo Mexican Mission to the WTO and Export Taxes under WTO Agreements. 2010. Disponível em: <https://www.tradelab.org/images/tradelab/ pdf/clinics/2016/Export_taxes_under_WTO_Agreements.pdf>. Acesso em: 09 set. 2018.

LEVY, S. Globalización económica. Ciudad de México: Editorial ISEF.2003.

MARCEAU, G. A History of Law and Lawyers in the GATT/WTO: The Development of the Rule of Law in the Multilateral Trading System. Cambridge United Kingdom: Cambridge University Press. 2015

MATSUSHITA, M. Export controls of natural resources and the WTO/GATT disciplines. Asian journal of WTO \& international health law and policy, vol. 6, n. 2, p. 281-312. 2011.

MILDNER, S; LAUSTER, G. Settling Trade Disputes over Natural Resources: Limitations of International Trade Law to Tackle Export Restrictions. Goettingen Journal of International, vol. 3, n. 1, p. 251-281. 2011

MINISTERIO DE COMERCIO INDUSTRIA Y TURISMO. Sistema Armonizado Decreto 2153. 2016. Disponível em: < http://www.mincit.gov.co/documentos/351/2016>. Acesso em: 15 de nov. 2018

MINDREAU, M. Del GATT a la OMC, 1947-2005 : la economía política internacional del sistema multilateral de comercio. Lima, Perú: Universidad del Pacífico, Centro de Investigación. 2005. 
MINISTERIO DE COMERCIO CHINO. Regulation of the People's Republic of China on the Administration of the Import and Export of Goods. 2002. Disponível em: $<$ http://en.pkulaw. cn/display.aspx?cgid=38108\&lib=law $>$. Acesso em: 15 de nov. 2018.

NARLIKAR, A., DAUNTON, M., \& STERN, R.. The Oxford Handbook on The World Trade Organization. New York: Oxford University Press.2012.

NELSON, D. Prospects for Constitutionalization of the WTO. World Trade Review, vol. 14,n. 1, p.135-153. 2015.

ODELL, J. Breaking deadlocks in international institutional negotiations: The WTO, Seattle, and Doha. International Studies Quarterly. vol. 53, n. 2, p.273-299.2009.

ORGANIZATION FOR ECONOMIC CO-OPERATION AND DEVELOPMENT (2012). Taking stock of measures restricting the export of raw materials: analysis of OECD inventory data. 2012. Disponível em: <http://www.oecd.org/officialdocuments/publicdisplaydocumentpdf/?cote $=$ TAD $/$ TC $/ \mathrm{WP} \% 282012 \% 2917 /$ FINAL\&docLanguage $=$ En $>$. Acesso em: 09 set. 2018.

ORGANIZACIÓN MUNDIAL DEL COMERCIO. Serie de acuerdos de la OMC Medidas Sanitarias y Fitosanitarias. 2010. Disponível em: $<$ https://www.wto.org/spanish/res_s/booksp_s/ agrmntseries4_sps_s.pdf $>$. Acesso em: 17 ago. 2018.

ORGANIZACIÓN MUNDIAL DEL COMERCIO. Los años del GATT: de La Habana a Marrakech. 2017. Disponível em: <https://www.wto.org/spanish/thewto_s/whatis_s/tif_s/fact4_s.htm>. Acesso em: 29 set. 2018.

ORGANIZACIÓN MUNDIAL DEL COMERCIO. Las Conferencias Ministeriales. 2017a. Disponível em: <https://www.wto.org/spanish/thewto_s/minist_s/minist_s.htm>. Acesso em: 15 ago. 2018.

ORGANIZACIÓN MUNDIAL DEL COMERCIO. La Ronda de Doha.. 2017b. Disponível em: < https://www.wto.org/spanish/tratop_s/dda_s/dda_s.htm >. Acesso em: 15 nov. 2018.

ORGANIZACIÓN MUNDIAL DEL COMERCIO. Diferencias planteadas en el marco del GATT. Obtenido de Organización Mundial de Comercio. 2017c. Disponível em: < https://www. wto.org/spanish/tratop_s/dispu_s/gt47ds_s.htm>. Acesso em: 09 set. 2018.

ORGANIZACIÓN MUNDIAL DEL COMERCIO. Lista cronológica de las diferencias. 2017d. Disponível em: < https://www.wto.org/spanish/tratop_s/dispu_s/dispu_status_s.htm >. Acesso em: 17 ago. 2018.

ONO, Y. Profitability of export restraint. Journal of International Economics, vol. 16, n. 3-4, p. 335-343. 1984.

PERE, G. Emerging markets - Emerging powers: Changing parameters for global economic governance. Internationale Politik und Gesellschaft, vol.1, n. 1, p. 36-51. 2005.

PIEROLA, F. Solución de diferencias ante la OMC: presente y perspectivas. Londres, Reino Unido: Cameron May. 2007.

REIS, R. The World Trade Organization. New York, Estados Unidos: Chesea House Publishers. 2009.

RESTREPO, L. La globalización de la economía, el crimen y la seguridad. Análisis Político, vol. 18, n. 53, p.22-38. 2005.

ROMM, J. Defining national security: the nonmilitary aspects. New York: Council on Foreign Relations Press.1993.

ROSE, A. Do WTO members have more liberal trade policy? Journal of International Economics, vol. 63, n. 2, p. 209-35. 2004.

SILVA, V. El camino hacia las nuevas negociaciones comerciales en la OMC (post Doha). Santiago de Chile: CEPAL ECLAC División de Comercio Internacional e Integración. 2001.

SOLLEDER, O. Trade Effects of Export Taxes. Obtenido de Graduate Institute of International and Development Studies Working Paper n. 08. 2013. Disponível em: $<$ http://graduateinstitute. ch/files/live/sites/iheid/files/sites/international_economics/shared/international_economics/ publications/working\%20papers/2013/HEIDWP08-2013.pdf>. Acesso em: 05 nov. 2018.

SUBRAMANIAN, A; WEI, S. The WTO promotes trade, strongly but unevenly. Journal of International Economics, vol 72, n. 1, p. 151-175.2007.

TORRES, J. The Regulatory Framework of Export Restrictions in WTO Law and Regional Free Trade Agreements . 2013. Obtenido de Institute for European Studies.Disponível em: $<$ http://aei.pitt.edu/60850/1/2013.8.pdf>. Acesso em: 05 nov. 2018. 
TUGORES, J. Economía internacional. Globalización e integración regional. Barcelona: MacGraw-Hill. 2002.

UNITED NATIONS CONFERENCE TRADE AND DEVELOPMENT. Internal Classification of Non-Tariff Measures. 2012. Disponível em: <http://unctad.org/en/PublicationsLibrary/ ditctab20122_en.pdf>. Acesso em: 29 set. 2018.

VALERO, Alicia; VALERO, Antonio. Physical geonomics: Combining the exergy and Hubbert peak analysis for predicting mineral resources depletion. Resources Conservation and Recycling, vol, 54, n. 12, p. 1074-1083.2010.

VAN DEN BOSSCHE, P; ZDOUC, W. The Law and Policy of the World Trade Organization. New York, Estados Unidos: Cambridge University Press. 2013.

YA QIN, J. Reforming WTO Discipline on Export Duties: Sovereignty over Natural Resources, Economic Development and Environmental Protection. Journal of World Trade, vol. 46, n. 5, p. 1147-1190.2012.

YA QUIN, J. "WTO-Plus" Obligations and Their Implications for the World Trade Organization Legal System An Appraisal of the China Accession Protocol. Journal of World Trade, vol. 37, n.1, p.483-522. 2003. 